\title{
К ВОПРОСУ О ФОРМАХ И МЕТОДАХ БОРЬБЫ С ПРЕСТУПНОСТЬЮ В РЫБНОЙ ОТРАСЛИ ОРГАНАМИ ВНУТРЕННИХ ДЕЛ ПРИМОРСКОГО КРАЯ НА РУБЕЖЕ ХХ-ХХІ ВВ
}

\section{TO THE QUESTION OF THE FORMS AND METHODS OF COMBATING CRIME IN THE FISHING INDUSTRY BY THE INTERNAL AFFAIRS AUTHORITIES OF PRIMORSKY KRAI AT THE TURN OF THE XX-XXI CC}

A. Vinogradov

Summary: In the article the activity of law-enforcement bodies of Primorskii territory on prevention and suppression of crimes in fish branch on a boundary of XX -XXI centuries is analyzed on the basis of archive sources and literature. The problems of development of the fish branch of the Far East of Russia, features of criminalization and counteraction to crime are examined. The activity of specialized operative divisions on combating the criminality in fish branch, forms and methods of combating are studied.

Keywords: internal affairs bodies, prevention and suppression of crimes in the fish branch, Primorsky Territory, specialized operative divisions, forms and methods of combating the economic criminality.
$\mathrm{B}$ одные биологические ресурсы России - это национальное достояние и основа продуктовой безопасности страны. Дальневосточный регион России обладает колоссальными запасами ценных пород морских животных и растений, рациональное освоение которых является актуальной и перспективной задачей общества.

Одной из проблем пользованиями морскими биоресурсами страны на рубеже XX-XXI вв. становится их незаконная промышленная добыча и сбыт в сопредельные государства, что причиняло значительный экономический и экологический ущерб. [15, с.131-137] Только с сентября по ноябрь 2000 года в камчатском бассейне пресечено контрабанды крабовой продукции в порты США и Японии объёмом более 150 тонн на сумму 16 млн. долларов США. [32, л.92-93.] В 2002 году в дальневосточном регионе с апреля по июль 137 организаций отправителей по подложным грузовым таможенным декларациям на 139 судах незаконно переместили в Японию морепродуктов стоимостью 9,7 млрд рублей. [33, л.31-36.] По оценкам Счетной палаты России, только за период 2000-2003 годы стоимость незаконно вывезенной в Япо-

\author{
Виноградов Андрей Михайлович \\ Старший преподаватель, Владивостокский филиал \\ ФГКОУ ВО «ДВЮИ МВД России» \\ philosophyworld@inbox.ru
}

Аннотация: В статье, на основе архивных источников и литературы анализируется деятельность органов внутренних дел Приморского края по предупреждению и пресечению преступлений в рыбной отрасли на рубеже XX-XXI Вв. Рассматриваются проблемы развития рыбной отрасли Дальнего Востока России, особенности криминализации и противодействия преступности. Изучается деятельность специализированных оперативных подразделений по борьбе с преступностью в рыбной отрасли, формы и методы борьбы.

Ключевые слова: органы внутренних дел, предупреждение и пресечение преступлений в рыбной отрасли, Приморский край, специализированные оперативные подразделения, формы и методы борьбы с экономической преступностью.

нию продукции рыбного промысла, добытой в исключительной экономической зоне России, в среднем за год, составила более чем 826 млн долларов США, что было равноценно трети стоимости товарной продукции рыбной отрасли России. [11] По некоторым оценкам в 2007 году 80 \% всех, выловленных в исключительной экономической зоне России биоресурсов, незаконно добыты и незаконно сбыты в портах сопредельных государств. [9, с.20-23.] При осуществлении незаконного промышленного рыболовства в акватории ДФО добываются не любые промысловые, а наиболее ценные виды морских животных - крабы (камчатский, опилио, берди, волосатый), морские ежи, нерка, кета и другие, в объёмах, в разы, превышающих предельно допустимые. В начале 2000-х ежегодный незаконный промысел живого морского ежа из районов лова близких к Японии - Южно-Курильской зоны, Западной и Восточной Сахалинской подзон, подзоны Приморья, превышал общий допустимый улов в 3-4 раза. [11]

Поэтому, защита водных биоресурсов от расхищения и уничтожения является важным направлением государственной политики по обеспечению экономической и 
экологической безопасности государства. Одна из ведущих ролей в этом отведена органам внутренних дел.

Органы внутренних дел Приморья накопили значительный опыт пресечения преступной деятельности в рыбной отрасли края, исследование которого имеет научное и практическое значение.

Вопросам противодействия экономической преступности органами внутренних дел, в дальневосточном регионе страны, в том числе в организованных формах, посвящен ряд исследований. [4, с.292-295, 5, с.120-123, 6, с.371-375, 8, с.200-207, 10, 13] В специальных исследованиях изучается процесс криминализации рыбной отрасли в ДФО, освещаются вопросы борьбы с незаконным оборотом водных биологических ресурсов. [2, с.4250, 3, с.26-37, 7, с.156-166, 15, с.131-137, 14, с.241-245, 9, с.20-23, 28, с.38-42] В тоже время, анализ публикаций по проблеме показывает, что опыт органов внутренних дел по предупреждению, и раскрытию экономических преступлений, в том числе в рыбной отрасли, изучен недостаточно. Требует изучения широкий спектр вопросов, открыт для исследования большой объём архивных материалов.

Органами внутренних дел в борьбе с преступностью применяются различные организационные формы: создание специализированного оперативного и (или) следственного подразделения, действующего по отдельному направлению [34, л.254-277.]; создание следственно-оперативной группы при расследовании уголовного дела; проведение оперативно-профилактических мероприятий - операций. В борьбе с экономической преступностью применяются все формы.

В органах внутренних дел задачи и функции по борьбе с экономической преступностью методами оперативно-разыскной деятельности осуществляют специализированные оперативные подразделения.

В 1991-1992 годы, в Приморье, специализированного подразделения по борьбе с преступностью в рыбной отрасли не создавалось. Отдел БПСЭ УВД Примкрайисполкома, созданный в 1991 году вместо управления БХСС, в своей структуре имел подотдел борьбы с преступностью на приоритетных направлениях. Как одну из ряда других, подотдел выполнял и задачу по пресечению преступлений в сфере пользования водными биоресурсами. [16, л.136-144, 17, л.65]

В начале 90-х годов XX века, государственный сектор рыбной отрасли страны разрушается. Посредством приватизации, государственные предприятия переходят в собственность частных лиц. Политика либерализации экономики и ослабления государственного контроля приводит к тому, что с середины 90-х годов 20 века, ос- новная доля средств производства рыбного промысла сосредотачивается в частном секторе. В рыбной отрасли Дальнего Востока в 1992-1994 годы приватизировано 204 предприятия рыбопромышленного комплекса, производивших до 89\% всей морепродукции региона, а с 1 января 1994 года до июня 1995 стали частными еще 126 предприятий. [12, с.11-12] В стремлении к максимизации прибыли владельцы рыбохозяйственных предприятий ориентируются на экспорт продукции за рубеж. Например, в 1992-1997 годы доля экспорта морепродукции составляла 62,3-81,3 \%. [12, с.11-12] Устойчивый заграничный рынок сбыта, прибыльность экспорта биоресурсов, приводит к развитию незаконного промысла морепродуктов в промышленных масштабах и их реализации в заграничных портах. Ситуация усугубляется установлением организованными преступными формированиями криминального контроля над рядом предприятий рыбохозяйственного комплекса региона.

Особенности функционирования дальневосточной рыбной промышленности - большие пространства акватории морского промысла, большое число участников, криминализация отрасли, обуславливали особенности организации правоохранительной деятельности в отрасли - межведомственное взаимодействие, достаточный объём сил и средств, задействованных в мероприятиях, специализация подразделений.

В 90-е годы XX века и 2000-е рыбохозяйственный комплекс Приморья, являлся крупнейшим не только на Дальнем Востоке, но и в России, включая в себя десятки организаций и более 1000 добывающих и перерабатывающих судов флота. [23, л.97-106] Для охвата такого числа судов на больших площадях акватории при пресечении незаконной добычи необходимы достаточные сила и средства, а для успешного правоохранительного воздействия на лиц, осуществляющих преступную деятельность в рыбной отрасли, необходимы эффективные оперативно-разыскных методы и профессионализм сотрудников. Поэтому, особое значение в борьбе с преступностью в рыбной отрасли приобретают операции и специализация подразделений ОВД.

В марте 1993 года, в УВД Приморского края, создано специализированное оперативное подразделение, непосредственно подчиненное УВД - отдел по борьбе с экономическими преступлениями в рыбной промышленности (далее Отдел), который стал выполнять задачи по выявлению и раскрытию хищений рыбы и морепродуктов, хозяйственных и должностных преступлений на судах в районах промысла и береговых объектах. [20, л.194-195].

Ежегодно в несколько этапов, в акватории в местах промысла, а также на реках Приморья в период нереста лососевых, при непосредственном участии Отдела, во 
взаимодействии с другими ведомствами, например ФСБ, ФПС, ФСНП, ГТК, Моринспекцией и рядом других, проводились оперативно-профилактические мероприятия (операции) под условным наименованием «Путина», обладающие большим превентивным потенциалом, позволяющие во взаимодействии увеличивать объёмы сил и средств правоохранительных органов, прилагаемых на отдельном направлении деятельности и одновременно охватывать значительную акваторию и большое число предприятий. [31, л.223-227, 37, л.118-126, 20, л.194-195, 23, л.97-106].

Только с апреля по сентябрь 1993 года сотрудниками Отдела выявлено 91 преступление, из которых 61 хищение рыбопродукции (11 из них в особо крупных размерах) выявлен и пресечен канал незаконного сбыта рыбной продукции в Южную Корею, пресечена деятельность 5 преступных групп. [19, л.12, 21, л.50] При проведении второго этапа «Путина-94» пресечено 43 преступления, из них 5 хищений рыбопродукции в особо крупных размерах, проверено 75 российских судов, выявлено укрытой от учета рыбы и морепродукции на сумму более 100 млн рублей. [18, л.275] При проведении первого этапа операции «Путина-96» выявлено и пресечено 130 преступлений, по которым ущерб составил 8,5 млрд рублей. Возмещено ущерба на сумму 7 млрд рублей. Проверено 165 судов, выявлено укрытой от учета рыбы и морепродукции на сумму 3,2 млрд рублей. [22, л.52] При проведении операции «Путина-97» выявлено 460 преступлений, материальный ущерб по которым, составил 12,7 млн деноминированных рублей, пресечено 5563 административных правонарушений, выявлено и оприходовано неучтённой продукции на сумму 8,9 млн деноминированных рублей. [23, л.97-106]

В 1996 году МВД России проведены мероприятия по совершенствованию структуры и штатов аппаратов МВД, ГУВД, УВД субъектов Российской Федерации. В составе которых, в едином структурном блоке криминальной милиции, созданы управления (отделы) по экономическим преступлениям, а в качестве подразделений подведомственных МВД, ГУВД, УВД - межрайонные отделы (отделения) по экономическим преступлениям. Так отдел по борьбе с экономическими преступлениями в рыбной промышленности при УВД Приморского края приобрел статус межрайонного, который сохранял до 1999 года. [ 24, л.90-93]

В середине 90-х годов XX века формируется новая стратегия правоохранительной деятельности в экономике - защита интересов России и обеспечение экономической безопасности государства. [30, л.40-82] Указом Президента России от 29 апреля 1996 года №608 одобрена Государственная стратегия экономической безопасности Российской Федерации. [1] 6 ноября 1997 года министром внутренних дел, генералом армии - Анатолием
Сергеевичем Куликовым издан приказ от №730 «О мерах по совершенствованию организации работы по борьбе с преступлениями в сфере экономики», заложивший основу организации деятельности специализированных оперативных подразделений по борьбе с противоправными деяниями, направленными на подрыв экономической безопасности страны. [35, л.185-189] Пресечение незаконного вывоза за рубеж стратегически важной продукции, в том числе рыбы, ракообразных, моллюсков, продуктов их переработки становится одним из приоритетных направлений деятельности службы по борьбе с экономической преступностью. В структуре Главного управления по экономическим преступлениям МВД России (ГУЭП МВД России) создаётся отдел по борьбе с преступлениями в сфере добычи, переработки и реализации водных биоресурсов. [36, л.124-128]

В июне 1999 года УВД Приморского края, реализуя государственную политику по обеспечению экономической безопасности государства в сфере пользования водными биоресурсами, реорганизует межведомственный отдел по борьбе с экономическими преступлениями в рыбной промышленности в управление по борьбе с экономическими преступлениями в рыбной отрасли УБЭП в рыбной отрасли при УВД (далее Управление). [24, л.90-93] Управление осуществляло борьбу с тяжкими преступлениями в рыбной отрасли - на добывающих, перерабатывающих и транспортных судах флота в районах промысла, на береговых объектах, в коммерческих структурах и сфере внешнеэкономической деятельности, а также осуществляло организационно методическое обеспечение деятельности подразделений по борьбе с экономическими преступлениями городских, районных ОВД края. [24, л.90-93]

В 1999-м и начале 2000-х Правительством России принимается ряд мер по обеспечению экономической безопасности государства в морских портах. Реализуя эти меры МВД России в апреле 2000 года принята Целевая программа по усилению борьбы с преступностью, обеспечению общественного порядка и безопасности в морских портах и организациях, занятых в сфере морской деятельности. [39, л.134-170] Принятыми мерами повышена результативность операций «Путина». В 1999 году силами УБЭП в рыбной отрасли при УВД Приморского края, во взаимодействии с другими подразделениями БЭП ОВД края и правоохранительными органами, выявлено 718 преступлений в рыбной отрасли Приморья, из них 275 хищений морепродукции. В 2000-м выявлено уже 818 преступлений, на 13,9\% больше, из них хищений морепродукции вскрыто 496, больше в 1,8 раза [25, л.248-250] Наращиваются усилия по пресечению тяжких и особо тяжких преступлений в рыбопромышленном комплексе. В 1999 году выявлено таких преступлений больше чем в предыдущем году - 129, а в 2000-м в 2,7 раза больше чем в 1999-м - 349. [25, л.248-250] 
Одним из приоритетных направлений деятельности подразделений БЭП дальневосточного региона и Приморского края в этот период становится проведение, во взаимодействии с другими правоохранительными органами, оперативно-разыскных и оперативно-профилактических мероприятий, по пресечению организованной преступности в морских портах и на предприятиях рыбной отрасли. Подразделениями БЭП края под руководством УБЭП в рыбной отрасли, во взаимодействии с РУБОП МВД по Приморскому краю, в 1999 году выявлено 34 преступления, совершенных в рыбопромышленном комплексе Приморья членами организованных преступных группировок (далее ОПГ) и группами лиц по предварительному сговору, из них 22 хищения имущества. В 2000 году таких преступлений выявлено в 3,2 раза больше - 108, а хищений имущества больше в 4,2 раза - 92. Выведено из-под криминального контроля ОПГ в 1999 году пять рыбопромышленных предприятий, в 2000-м семь. [25, л.248-250]

К 2002 году изменен статус УБЭП в рыбной отрасли при УВД Приморского края, которое реорганизованного в межрайонное управление по борьбе с экономическими преступлениями в рыбной отрасли при УВД Приморского края. [26, л.132-165] Структура и штаты подразделения не изменены, но увеличены оклады денежного содержания сотрудников.

В 1999 году, в целях усиления оперативно-разыскной деятельности, в ГУБЭП МВД России внедряется новая форма структурно-штатного построения специализированного оперативного подразделения - оперативно-разыскная часть (далее ОРЧ). [38, л.220-226] В апреле 2003 года создана ОРЧ криминальной милиции по линии борьбы с экономическими преступлениями в рыбной отрасли, непосредственно подчиненная УВД Приморского края. Приказом УВД от 16 апреля №772 утверждена структура и штатное расписание ОРЧ. [27, л.87-91] УБЭП в рыбной отрасли ликвидировано, все штаты сокращены. ОРЧ, с учетом приобретенного опыта по борь- бе с экономической преступностью в изменяющихся условиях рыбного промысла в крае, осуществляло борьбу с тяжкими и особо тяжкими преступлениями - на добывающих и транспортных судах флота, на перерабатывающих предприятиях, на судоремонтных заводах, в сфере внешнеэкономической деятельности, связанной с рыбным промыслом. Кроме этого ОРч, для выявления тенденций развития преступности в рыбной отрасли края, начинает осуществляться анализ и контроль промысла. $[27$, л.87-91]

Таким образом. На рубеже XX-XXI вв. борьба с преступностью в рыбной отрасли становится одним из приоритетных направлений правоохранительной деятельности ОВД в экономике, особенно Дальнего Востока России, так как одной из общественно опасных тенденций в отрасли становится незаконная добыча морских биоресурсов и их сбыт в портах сопредельных государств, причиняющая значительный экономический и экологический ущерб.

Органами внутренних дел в борьбе с преступностью в рыбной отрасли успешно применялись формы, основанные на межведомственном взаимодействии и специализации оперативных подразделений.

В УВД Приморского края на рубеже XX-XXI вВ. действовало специализированное оперативное подразделение по борьбе с преступностью в рыбной отрасли края, структура которого, штаты изменялись в соответствии с государственной политикой, ситуацией в отрасли и накопленным опытом выявления и пресечения экономических преступлений.

Принимаемые УВД Приморского края организационные меры, проводимые оперативно-профилактические мероприятия, внесли существенный вклад в обеспечение экономической безопасности государства и защиты его интересов в сфере пользования биоресурсами Дальнего Востока.

\section{ЛИТЕРАТУРА}

1. Указ Президента Российской Федерации от 29 апреля 1996 г. №608 «0 Государственной стратегии экономической безопасности Российской Федерации (Основных положениях)» // Собрание законодательства РФ. 1996. № 18. Ст. 2117.

2. Бадаев, А.Г. Экономическая безопасность рыбопромышленного комплекса России (на примере Дальневосточного федерального округа) / А.Г. Бадаев, А.С. Русаков // Вестник Академии экономической безопасности МВД России. 2010. № 8. С. 42-50.

3. Вайсман, А.Л. Нелегальный оборот флоры и фауны между Дальним Востоком России и Северо-Восточным Китаем // 0йкумена. 2013. № 3 (26). С. $26-37$.

4. Вачаев, Н.А. Состояние криминогенной обстановки в Приморском крае и особенности предупреждения региональной преступности / Н.А. Вачаев, Г.Н. Вихляева, Н.А. Шабельникова // Актуальные проблемы борьбы с преступностью в Сибирском регионе: материалы междунар. науч.-практ. конф., Красноярск, 5-6 февр. 2004 г. Ч. 1. Красноярск: РИО СибЮИ МВД России, 2004. С. 292-295.

5. Иванов, Е.В. Криминологические особенности преступности в Приморском крае (1985-1991 гг.) // Актуальные проблемы борьбы с преступностью в Сибирском регионе: материалы XXII междунар. науч.-практ. конф. Красноярск: РИО СибЮИ МВД России, 2019. С. 120-123.

6. К Коровников, И.П. Отечественный опыт противодействия организованным преступным группировкам // Культурно-историческое наследие России и 
стран Азиатско-Тихоокеанского региона: исследование и сохранение: материалы междунар. науч.-практ. конф., посвящ. 100-летию высш. ист. образования на Дальнем Востоке России, Владивосток, 16-17 окт. 2018 г. Хабаровск: РИО ДВЮИ МВД России, 2018. С. 371-375.

7. Ларичев, В.Д. Криминогенная ситуация и проблемы борьбы с преступлениями в сфере оборота водных биологических ресурсов / В.Д. ЛаричеВ, Ю.С. Варанкина // Общество и право. 2009. № 3 (25). С.156-166.

8. Некрытый, В.В. История органов внутренних дел на Дальнем Востоке России в исследованиях и библиографии // Россия и Китай: история и перспективы сотрудничества: материалы IX междунар. науч.-практ. конф. Вып. 9., ч. 1 / отв. ред. О.А. Шеломихин. Благовещенск: Изд-во БГПУ, 2019. С. $200-207$.

9. Овчинский, В. Территория «свободной охоты» // Огонек. 2007. № 46. С. 20-23.

10. Организованная преступность Дальнего Востока: региональные черты и хроника событий / отв. ред. В.А. Номоконов. Владивосток: Изд-во Дальневост. федерал. ун-та, 2011.516 с.

11. Отчет о результатах проверки эффективности функционирования Российской части Российско-Японской комиссии по урегулированию претензий, связанных с рыболовством, в части предотвращения в 2001-2002 годах поставок браконьерской продукции морского рыбного промысла, добытой в исключительной экономической зоне Российской Федерации, в морские рыбные порты Японии: из решения Коллегии Счетной палаты Российской Федерации от 19 декабря 2003 года № 44 (369) [Электронный ресурc]. URL: https://ach.gov.ru/checks/proverka-effektivnosti-funktsionirovaniya-rossiyskoychasti-rossiysko-yaponskoy-komissii-po-uregulir.

12. Римская, Т.Г. Развитие рыбной промышленности Дальнего Востока в условиях рыночных реформ: Середина 1980-х - 2004 гг.: автореф. дис. ... канд. ист. наук: 07.00.02 / С.-Петерб. гос. ун-т. Санкт-Петербург, 2005. 17 с.

13. Саркисов, Д.Н. Экономическая преступность в ракурсе личной безопасности жителей Дальнего Востока: монография / Д.Н. Саркисов, М.В. Жерновой, А.Н. Сухаренко. Владивосток: Дальневост. федерал. ун-т, 2014. 102 с.

14. Смирнов, А.В. Современные проблемы уголовно-правовой борьбы с незаконной добычей водных животных и растений и незаконной охотой // Вестник АГТУ. 2006. № 5. С. 241-245.

15. Сухаренко, А.Н. Транснациональные аспекты незаконного оборота водных биоресурсов на Дальнем Востоке // Изв. Вост. ин-та. 2012. № 2. С. 131-137.

16. Текущий архив УМВД России по Приморскому краю (ТА УМВД России по ПК). Ф. 12. Оп. 2. Д. 517. Л. 136-144.

17. ТА УМВД России по ПК. Ф. 12. Оп. 2. Д. 523. Л. 65.

18. ТА УМВД России по ПК. Ф. 12. Оп. 3. Д. 64. Л. 275.

19. ТА УМВД России по ПК. Ф. 12. 0п. 3. Д. 66. Л. 12.

20. ТА УМВД России по ПК. Ф. 12. Оп. 3. Д. 76. Л. 194-195.

21. ТА УМВД России по ПК. Ф. 12. Оп. 3. Д. 78. Л. 50.

22. ТА УМВД России по ПК. Ф. 12. Оп. 3. Д. 157. Л. 52.

23. ТА УМВД России по ПК. Ф. 12. Оп. 3. Д. 217. Л. 97-106.

24. ТА УМВД России по ПК. Ф. 12. Оп. 4. Д. 9. Л. 90-93.

25. ТА УМВД России по ПК. Ф. 12. 0п. 12. Д. 10. Л. 248-250.

26. ТА УМВД России по ПК. Ф. 12. Оп. 15. Д. 21. Л. 132-165.

27. ТА УМВД России по ПК. Ф. 12. Оп. 19. Д. 16. Л. 87-91.

28. Хренков, 0.В. Незаконный оборот морских биоресурсов: российско-китайский аспект // Ойкумена. 2013. № 3 (26). С. $38-42$.

29. Центральный Архив МВД РФ (ЦА МВД РФ). Ф. 133. Оп. 1. Д. 9. Л. 34-35.

30. ЦА МВДРФ. Ф. 133. 0п. 1. Д. 51. Л. 40-82.

31. ЦА МВДРФ. Ф. 133. Оп. 1. Д. 112. Л.223-227.

32. ЦА МВД РФ. Ф. 133. Оп. 1. Д. 122. Л. 92-93.

33. ЦА МВД РФ. Ф. 133. Оп. 1.Д. 223. Л. 31-36.

34. ЦА МВДРФ. Ф. 163. Оп. 1. Д. 183. Л. 254-277.

35. ЦА МВДРФ. Ф. 163. Оп. 1. Д. 230. Л. 185-189.

36. ЦА МВДРФ. Ф. 163. 0п. 1. Д. 246. Л. 124-128.

37. ЦА МВДРФ. Ф. 163. Оп. 1. Д. 251. Л. 118-126.

38. ЦА МВДРФ. Ф. 163. Оп. 1. Д. 299. Л. 220-226.

39. ЦА МВДРФ. Ф. 163. 0п. 1.Д. 318. Л. 134-170.

( ) Виноградов Андрей Михайлович (philosophyworld@inbox.ru). Журнал «Современная наука: актуальные проблемы теории и практики» 